\title{
Women with a Preterm Cesarean Have High Rates of Successful Trial of Labor in a Subsequent Term Pregnancy
}

Citation for published version (APA):

Rietveld, A. L., Heestermans, L. A. P. H., Kazemier, B. M., Teunissen, P. W., \& de Groot, C. J. M. (2019). Women with a Preterm Cesarean Have High Rates of Successful Trial of Labor in a Subsequent Term Pregnancy. American Journal of Perinatology, 36(7), 709-714. https://doi.org/10.1055/s-0038-1675155

Document status and date:

Published: 01/06/2019

DOI:

10.1055/s-0038-1675155

Document Version:

Publisher's PDF, also known as Version of record

Document license:

Taverne

Please check the document version of this publication:

- A submitted manuscript is the version of the article upon submission and before peer-review. There can be important differences between the submitted version and the official published version of record.

People interested in the research are advised to contact the author for the final version of the publication, or visit the DOI to the publisher's website.

- The final author version and the galley proof are versions of the publication after peer review.

- The final published version features the final layout of the paper including the volume, issue and page numbers.

Link to publication

\footnotetext{
General rights rights.

- You may freely distribute the URL identifying the publication in the public portal. please follow below link for the End User Agreement:

www.umlib.nl/taverne-license

Take down policy

If you believe that this document breaches copyright please contact us at:

repository@maastrichtuniversity.nl

providing details and we will investigate your claim.
}

Copyright and moral rights for the publications made accessible in the public portal are retained by the authors and/or other copyright owners and it is a condition of accessing publications that users recognise and abide by the legal requirements associated with these

- Users may download and print one copy of any publication from the public portal for the purpose of private study or research.

- You may not further distribute the material or use it for any profit-making activity or commercial gain

If the publication is distributed under the terms of Article $25 \mathrm{fa}$ of the Dutch Copyright Act, indicated by the "Taverne" license above, 


\title{
Women with a Preterm Cesarean Have High Rates of Successful Trial of Labor in a Subsequent Term Pregnancy
}

\author{
Anna L. Rietveld, MD ${ }^{1, *}$ Lotte A. P. H. Heestermans, MD ${ }^{1, *}$ Brenda M. Kazemier, MD, PhD ${ }^{2}$ \\ Pim W. Teunissen, MD, $\mathrm{PhD}^{1,3}$ Christianne J. M. de Groot, MD, $\mathrm{PhD}^{1}$
}

${ }^{1}$ Department of Obstetrics and Gynecology, Amsterdam UMC,
Vrije Universiteit Amsterdam, Amsterdam, The Netherlands
${ }^{2}$ Department of Obstetrics and Gynecology, Amsterdam UMC,
University of Amsterdam, Amsterdam, The Netherlands
${ }^{3}$ School of Health Professions Education (SHE), Maastricht University,
Maastricht, The Netherlands

Am J Perinatol 2019;36:709-714.

\author{
Address for correspondence Anna L. Rietveld, MD, Suite ZH 8F022, \\ De Boelelaan 1117, 1081 HV Amsterdam, The Netherlands \\ (e-mail: al.rietveld@vumc.nl).
}

\begin{abstract}
Keywords

- cesarean delivery

- trial of labor

- vaginal birth after cesarean

- preterm cesarean

Objective The rate of cesareans has increased worldwide. Therefore, an increasing number of women has to decide how to deliver in a subsequent pregnancy. Individualized information on risks and success chances is helpful. This study investigates the effect of a preterm cesarean on success of subsequent term trial of labor.

Study Design Ten-year Dutch cohort (2000-2009) of women with one previous cesarean and a subsequent term trial of labor. Subgroups were made based on gestational age at first cesarean delivery $(25-28,28-30,30-32$ and 32-34 weeks) and stratified based the way in which second delivery started. Rates of vaginal deliveries, maternal, and neonatal outcomes were compared with women who had a first-term cesarean (37-43 weeks).

Results Four thousand three-hundred forty-two women delivered by preterm cesarean in the first pregnancy. These women had high rates of successful trial of labor, both after spontaneous onset (86.2-96.2\%) and induction (72.8-75.4\%). Rates of adverse outcomes were low and similar compared with women with a previous term cesarean. Conclusion In this 10-year nationwide cohort, women with a preterm first cesarean who opted for trial of labor in a subsequent pregnancy had high rates of successful trial of labor.
\end{abstract}

Worldwide, the rate of cesarean deliveries is increasing, from $6.7 \%$ in 1990 to $19.1 \%$ in $2014 .^{1}$ Consequently, women and gynecologists are increasingly confronted with the question how to deliver in a subsequent pregnancy. Both trial of labor after cesarean and planned cesarean delivery have certain risks and benefits. Trial of labor carries, among others, the maternal risk of uterine rupture and the neonatal risk of hypoxicischemic encephalopathy. ${ }^{2}$ Cesarean deliveries are associated

* The first two authors contributed equally to the article. with a higher maternal risk of infection, puerperal venous thromboembolism and anesthetic complications, and a higher neonatal risk of respiratory distress syndrome, as compared with vaginal delivery. ${ }^{3-5}$ The decision on how to deliver in a postcesarean pregnancy is usually made by the woman, her partner, and her obstetrician. The American as well as Dutch guidelines describe women who are good candidates for planned trial of labor to be women in whom the balance between risks and success chance is acceptable to both herself and the obstetrician. ${ }^{6,7}$ In this regard, individualized

Copyright $\odot 2019$ by Thieme Medical Publishers, Inc., 333 Seventh Avenue, New York, NY 10001, USA.

DOI https://doi.org/ 10.1055/s-0038-1675155. ISSN $0735-1631$.
January 30, 2018

accepted after revision

September 3, 2018

published online

October 29, 2018 
information on the chance of success is desired. ${ }^{8}$ Many factors are described to influence success rate of trial of labor, such as maternal age, body mass index, ethnicity, mode of onset of labor, history of vaginal delivery, and neonatal birthweight. ${ }^{6}$ The role of a previous preterm cesarean has also been investigated as a possible influencer of trial of labor success. ${ }^{9-11}$ Prematurity in a previous cesarean is presumed to negatively influence vaginal birth success chance. Theoretically, the damage that is done when an incision is made in a preterm, undeveloped lower uterine segment might be more extended than in a term, fully developed lower uterine segment. This additional damage might prompt (the suspicion of) uterine rupture during a next trial of labor. ${ }^{12}$ Up until now, studies on this subject include small samples or lack a subdivision into multiple gestational age groups., ${ }^{9,10}$ Therefore, to include gestational age of the previous cesarean in antepartum counseling and intrapartum decision-making, more detailed information is needed. This study aims to assess the effect of a previous preterm cesarean on chance of success of a trial of labor in a subsequent pregnancy.

\section{Materials and Methods}

\section{Study Population}

We studied women with one previous cesarean and no history of vaginal birth who opted for a trial of labor in their subsequent, term, pregnancy. Women who had a previous preterm cesarean were compared with women who had a previous term cesarean. Data were extracted from the Netherlands Perinatal Registry (PRN). In this database, information about pregnancies, deliveries, and neonatal outcomes until 28 days after birth is collected. All data in the PRN are registered routinely by caregivers during prenatal care, delivery, and the neonatal period. Women are informed their information is recorded in the database and they may opt out. Data are sent to a national office for several consistency checks. The data of $\sim 95 \%$ of all pregnancies and deliveries in the Netherlands are registered in the PRN. ${ }^{13}$ The PRN is divided in three registries, a midwifery registry, an obstetrics registry, and a neonatology registry. A validated linkage procedure was used to link the three different registries. ${ }^{14,15}$ Due to the fact that the information about pregnancies, deliveries, and neonatal outcomes is registered on child level, there is no maternal identifier available. Consequently, an additional step was necessary to follow up on outcome of next pregnancies of the same mother. To achieve this, a longitudinal probabilistic linkage procedure was used to link all pregnancies and children of one mother. The linkage procedure is described by Schaaf et al. ${ }^{16}$ This procedure was completed up until December 31st, 2009 at the moment of our analysis. Thus, in our analysis, both the first and second pregnancy and delivery were between January 1, 2000 and December 31, 2009 in the Netherlands. The PRN approved usage of the database for our study (approval number 16.75).

We excluded women with twin pregnancies in first or second pregnancy, fetal congenital anomalies in first or second delivery, antepartum fetal death in second delivery, breech position in second delivery, a first cesarean before 25 and after 37 weeks of gestational for the study population and a first cesarean before 37 weeks and after $42+6$ weeks of gestational for the reference group, a second delivery before 37 or after $42+6$ weeks of gestational, and an elective repeat cesarean in second delivery. The study population was divided in subgroups based on gestational age at first cesarean delivery: $25+0$ till $27+6$ weeks, $28+0$ till $29+6,30+0$ till $31+6,32+0$ till $33+6$, and $34+0$ till $36+6$. The sixth group was the reference group with a gestational age of $37+0$ till $42+6$ weeks. The first group was chosen based on the assumption that the lower uterine segment has not yet been formed during the late second and the early third trimester of pregnancy, so a cesarean during this period could be considered a corporeal incision. ${ }^{17}$ Because it is unclear if there is a certain gestational age at which the effect on a following trial of labor is comparable with a cesarean in the term period, we decided to break the remaining group in subgroups of 2 weeks. We stratified for mode of start of delivery (either spontaneous or by induction), since induction is strongly associated with decreased trial of labor success. ${ }^{18}$ Baseline characteristics were maternal age at second delivery, ethnicity, socioeconomic status, cesarean performed during labor in first pregnancy, induction of labor at second delivery, gestational age at second delivery, and macrosomia (birthweight above 4500 g) at second pregnancy. The primary outcome was vaginal delivery, either spontaneously or assisted by vacuum/forceps. Secondary maternal outcomes were uterine rupture and postpartum hemorrhage. Secondary neonatal outcomes were defined as Apgar score $<7$ after 5 minutes, perinatal death, and respiratory distress syndrome. These outcomes were chosen for their clinical importance and accurate listing in the database, an exception being uterine rupture, which was not compulsory to score.

\section{Statistical Analysis}

Statistical Analysis Software 9.2 (SAS Institute Inc., Cary, NC) was used to analyze the results. We tested for statistically significant differences in patients' characteristics by using an analysis of variance test for continuous data and the chi-square test for discrete data. For comparing the success rate of trial of labor between the subgroups, a multivariate logistic regression analysis was performed, adjusting for maternal age at second delivery, ethnicity, socioeconomic status, and macrosomia in second delivery. ${ }^{6}$ To compare the maternal and neonatal outcomes, we combined the groups of $25+0$ till $27+6$ weeks, $28+0$ till $29+6,30+0$ till $31+6$ into one group of $25+0$ till $31+6$ weeks. This was done to increase power. We used the chi-square test. $p$-values less than 0.05 were considered statistically significant.

\section{Results}

Incidence of Preterm Cesarean and Subsequent Term Trial of Labor

-Fig. 1 shows the flow diagram of data extraction of our study population from the PRN. Our cohort consisted of 41 745 pregnant women with a previous cesarean between 25 and 43 weeks of gestation and a trial of labor in their second 


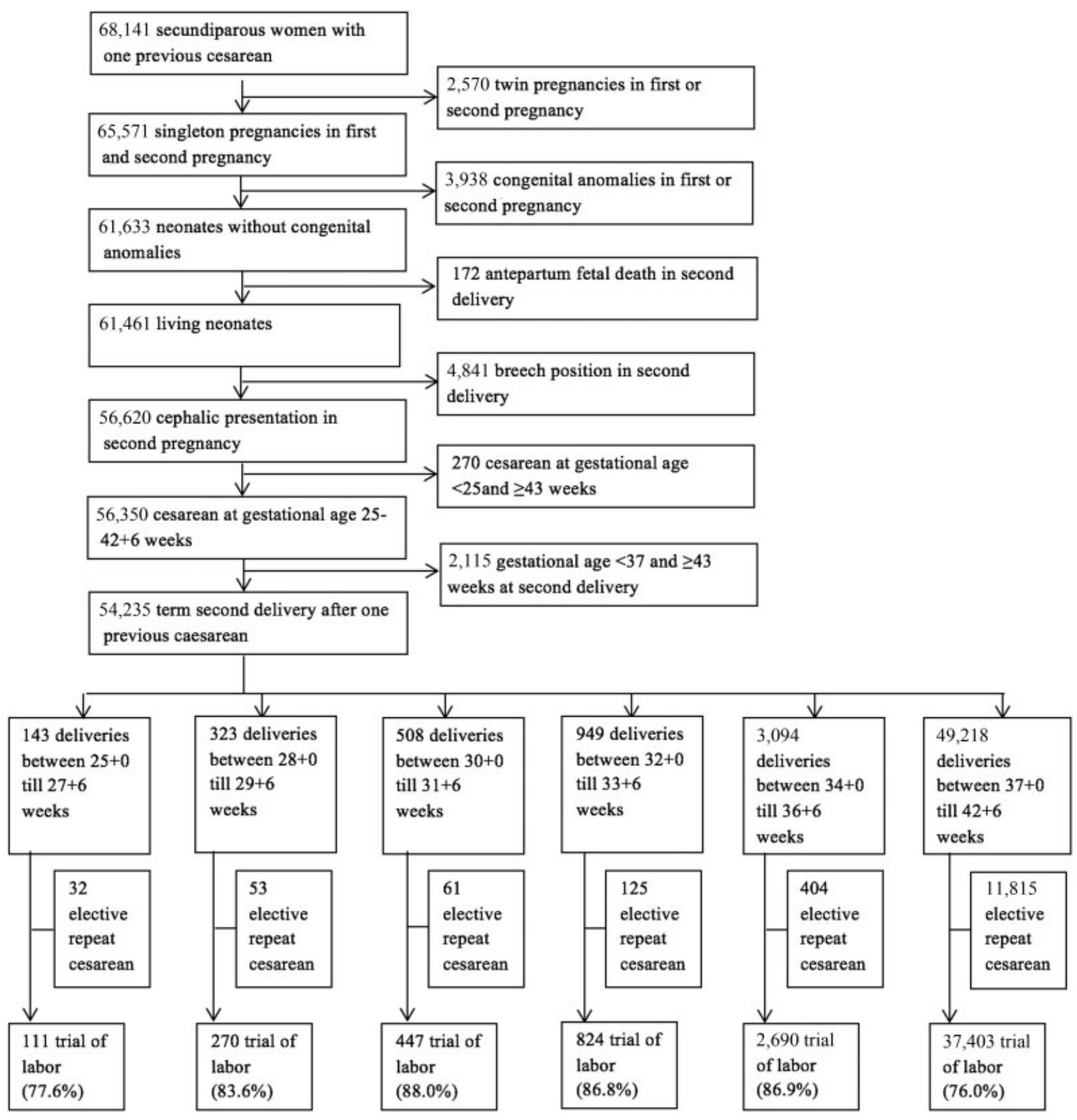

Fig. 1 Extraction of study population from the Netherlands Perinatal Registry.

delivery between 37 and 43 weeks. As depicted in - Fig. 1, in subgroups with a first preterm cesarean, 77.6 to $88.0 \%$ had a trial of labor.

\section{Demographic Characteristics}

- Table 1 reports demographic characteristics, obstetrical history, and characteristics of the second pregnancy for each of the six gestational age subgroups. All characteristics differed significantly between the groups.

\section{Success Rates of Trial of Labor}

-Table 2 reports success rates of trial of labor per first cesarean gestational age group for the whole group, the group with spontaneous labor onset, and the induced group. Success rates were 80.4 to $83.8 \%$ for women with a preterm first cesarean. When considering women with spontaneous labor onsets only, success rates were 86.2 to $96.2 \%$, higher than success rates for women who were induced (72.8-75.4\%). As compared with women with a previous term cesarean, success rates differed significantly, except for the induced women with a history of preterm cesarean between 25 and 32 weeks. Multivariate analysis, used to adjust for known confounders, showed no differences in these effects. - Table 3 shows maternal and neonatal outcomes of trial of labor after cesarean in second pregnancy per gestational age in first delivery. Adverse outcomes were rare and no statistically significant differences in adverse outcomes were found between term or preterm first cesareans. 
712 Effect of a Preterm Cesarean on Subsequent Term Trial of Labor Rietveld et al.

Table 1 Baseline characteristics

\begin{tabular}{|c|c|c|c|c|c|c|c|}
\hline & \multicolumn{7}{|c|}{ Gestational age at first cesarean delivery (weeks) } \\
\hline & $\begin{array}{l}25-28 \\
(n=111)\end{array}$ & $\begin{array}{l}28-30 \\
(n=270)\end{array}$ & $\begin{array}{l}30-32 \\
(n=447)\end{array}$ & $\begin{array}{l}32-34 \\
(n=824)\end{array}$ & $\begin{array}{l}34-37 \\
(n=2690)\end{array}$ & $\begin{array}{l}37-43 \\
(n=37,403)\end{array}$ & $p$-Value \\
\hline \multicolumn{8}{|c|}{ Maternal characteristics at second delivery } \\
\hline Age in years, mean (SD) & $30.3(4.26)$ & $30.6(4.75)$ & $31.0(4.39)$ & $31.2(4.28)$ & $31.6(4.20)$ & $31.9(4.04)$ & $<0.01$ \\
\hline Caucasian ethnicity & $101(91.0)$ & $232(85.9)$ & $408(91.3)$ & $743(90.2)$ & $2451(91.1)$ & $33364(89.20)$ & 0.01 \\
\hline Low SES & $28(25.2)$ & $70(25.9)$ & $95(21.3)$ & $173(21.0)$ & $494(18.4)$ & 7439 (19.9) & 0.02 \\
\hline \multicolumn{8}{|l|}{ First delivery characteristics } \\
\hline Cesarean during labor & $24(21.6)$ & $27(10)$ & $40(8.9)$ & $169(20.5)$ & $1293(48.1)$ & $26.626(71.2)$ & $<0.01$ \\
\hline \multicolumn{8}{|c|}{ Second pregnancy and delivery characteristics } \\
\hline Induction of labor & $59(53.2)$ & $139(51.5)$ & $239(53.5)$ & $431(52.3)$ & $1178(43.8)$ & $16030(42.9)$ & $<0.01$ \\
\hline GA second delivery, weeks & $39.0(1.30)$ & $39.1(1.20)$ & $39.2(1.25)$ & $39.2(1.28)$ & $39.2(1.30)$ & $39.7(1.19)$ & $<0.01$ \\
\hline Macrosomia ${ }^{a}$ & $3(2.70)$ & $2(0.74)$ & $5(1.12)$ & $14(1.70)$ & $48(1.78)$ & $1527(4.08)$ & $<0.01$ \\
\hline Suspected fetal distress & $30(27.0)$ & $62(23.0)$ & $99(22.2)$ & $177(21.5)$ & $560(20.8)$ & $8329(22.3)$ & $<0.01$ \\
\hline
\end{tabular}

Abbreviations: GA, gestational age; HD, hypertensive disorder; SES, socioeconomic status; SD, standard deviation.

Note: Data are presented as number (percentage) unless indicated otherwise.

${ }^{a}$ Birthweight above $4500 \mathrm{~g}$.

Table 2 Association between gestational age at first delivery and success of TOLAC in second delivery, stratified by type of labor onset

\begin{tabular}{|l|l|l|l|l|l|l|}
\hline $\begin{array}{l}\text { Gestational age at } \\
\text { first cesarean } \\
\text { (weeks) }\end{array}$ & $\begin{array}{l}\text { Total }(\boldsymbol{n}=\mathbf{4 1 , 7 4 5 )} \\
\text { Successful TOLAC }\end{array}$ & $\begin{array}{l}\text { Total aOR } \\
(\mathbf{9 5 \%} \mathrm{Cl})^{\mathrm{a}}\end{array}$ & $\begin{array}{l}\text { Spontaneous } \\
(\boldsymbol{n}=\mathbf{2 3 , 6 6 9 )} \\
\text { Successful TOLAC }\end{array}$ & $\begin{array}{l}\text { Spontaneous } \\
\text { aOR }(\mathbf{9 5 \%} \mathrm{Cl})^{\mathrm{a}}\end{array}$ & $\begin{array}{l}\text { Induction } \\
(\boldsymbol{n}=\mathbf{1 8 , 0 7 6}) \\
\text { Successful TOLAC }\end{array}$ & $\begin{array}{l}\text { Induction aOR } \\
(\mathbf{9 5 \%} \mathrm{Cl})^{\mathrm{a}}\end{array}$ \\
\hline $25-28(n=111)$ & $93(83.8)$ & $1.98(1.19-3.30)$ & $50(96.2)$ & $8.54(2.07-35.2)$ & $43(72.9)$ & $1.18(0.66-2.12)$ \\
\hline $28-30(n=270)$ & $217(80.4)$ & $1.57(1.16-2.13)$ & $113(86.3)$ & $2.06(1.25-3.39)$ & $104(74.8)$ & $1.38(0.94-2.03)$ \\
\hline $30-32(n=447)$ & $359(80.5)$ & $1.54(1.22-1.95)$ & $185(88.9)$ & $2.68(1.74-4.15)$ & $174(72.8)$ & $1.19(0.89-1.58)$ \\
\hline $32-34(n=824)$ & $670(81.3)$ & $1.67(1.40-2.00)$ & $348(88.6)$ & $2.61(1.91-3.58)$ & $322(74.7)$ & $1.33(1.07-1.66)$ \\
\hline $34-37(n=2690)$ & $2191(81.4)$ & $1.69(1.53-1.87)$ & $1303(86.2)$ & $2.08(1.79-2.42)$ & $888(75.4)$ & $1.41(1.23-1.62)$ \\
\hline $37-43(n=37,403)$ & $26,702(71.4)$ & Reference & $15,859(74.2)$ & Reference & $10,843(67.6)$ & Reference \\
\hline
\end{tabular}

Abbreviations: $\mathrm{Cl}$, confidence interval; aOR, adjusted odds ratio; TOLAC, trial of labor after cesarean.

Note: Data are presented as number (percentage).

aMultivariate models included the following covariates: maternal age in second delivery, low socioeconomic status (yes/no), Caucasian ethnicity (yes/no), macrosomia in second pregnancy (yes/no).

Table 3 Maternal and neonatal outcomes of TOLAC in second pregnancy per gestational age in first delivery

\begin{tabular}{|c|c|c|c|c|c|}
\hline & \multicolumn{5}{|c|}{ Gestational age at cesarean delivery (weeks) } \\
\hline & $\begin{array}{l}25-32 \\
(n=828)\end{array}$ & $\begin{array}{l}32-34 \\
(n=824)\end{array}$ & $\begin{array}{l}34-37 \\
(n=2690)\end{array}$ & $\begin{array}{l}37-43 \\
(n=37403)\end{array}$ & $p$-Value \\
\hline \multicolumn{6}{|l|}{ Maternal outcomes } \\
\hline Uterine rupture & $3(0.36)$ & $0(0.00)$ & $7(0.26)$ & $72(0.19)$ & 0.34 \\
\hline $\mathrm{HPP}^{\mathrm{a}}$ & $49(5.92)$ & $49(5.95)$ & $173(6.43)$ & $2374(6.35)$ & 0.92 \\
\hline \multicolumn{6}{|l|}{ Neonatal outcomes } \\
\hline 5-minute Apgar $<7$ & $7(0.85)$ & $11(1.33)$ & $36(1.34)$ & $443(1.18)$ & 0.68 \\
\hline Perinatal death ${ }^{\mathrm{b}}$ & $0(0.00)$ & $1(0.12)$ & $1(0.04)$ & $42(0.10)$ & 0.52 \\
\hline IRDS & $5(0.60)$ & $1(0.12)$ & $13(0.48)$ & $188(0.50)$ & 0.46 \\
\hline
\end{tabular}

Abbreviations: IRDS, infant respiratory distress syndrome; TOLAC, trial of labor after cesarean.

Note: Data are presented as number (percentage) .

${ }^{a} H P P:$ hemorrhage postpartum (defined as $>1 \mathrm{~L}$ blood loss).

${ }^{\mathrm{b}}$ Death during delivery and until 28 days after birth. 


\section{Comment}

\section{Main Findings}

In this large nationwide 10 -year cohort study, we demonstrated that women in a term pregnancy who opt for trial of labor after a previous preterm cesarean have high success rates, that vary between 72.8 and $96.2 \%$, depending on gestational age at first cesarean and the way in which the second delivery started (either spontaneous or by induction).

\section{Interpretation}

Previous smaller studies evaluated the effect of a preterm cesarean on trial of labor. Binder et al found that in a group of 166 women with a previous high placed U-incision between weeks 25 and 29, 72\% had a successful vaginal delivery after previous preterm caesarean. ${ }^{9}$ Kwee et al found a success rate of $86 \%$ in a group of 93 women who attempted vaginal delivery after a cesarean between 26 and 34 weeks. ${ }^{10}$ Harper et al compared success rates of 508 women who had a first cesarean before 34 weeks to 12027 women with first cesareans after 34 weeks. The rate of successful vaginal birth in the preterm group was $82 \%$, compared with $75 \%$ in the term group. ${ }^{11}$ Our study adds the subdivision into multiple subcategories of prematurity with a fair amount of cases in each group, contributing to the robustness of the finding that preterm cesarean does not prompt lower success rates of subsequent trial of labor.

The explanation for the higher success rates in comparison to women with a previous term cesarean might be the indication for the first cesarean. The reference group of women with a first-term cesarean contained relatively more women with a first cesarean that was performed during labor, for instance, for lack of progress. They, thus, have lower a priori chances on delivering vaginally as compared with women who did not (have the chance to) try to deliver vaginally. ${ }^{19}$ Unfortunately, in our database, the indication for the first cesarean is not registered on a level any further than whether the cesarean was performed before or during labor. However, besides considering the relative success chances, it is just as informative to look at the absolute success chances of women with a previous preterm cesarean. They have fairly high success chances, with roughly four in every five women succeeding in vaginal birth.

It is notable that in the group of women with a preterm first cesarean between $28+0$ and $31+6$ weeks who opt for trial of labor in a next term pregnancy, only 9 to $10 \%$ had a previous cesarean during labor. This means that the other $90 \%$ had a previous cesarean before labor started. An explanation for this observation cannot be found in selection bias, since $86 \%$ of women in this group opted for trial of labor in the next term pregnancy. In the PRN, it is compulsory to score if a woman was in labor or not. This observation raises the question how care providers declare a woman to be in labor and what the reasons were for performing cesarean in this group.

Since both success rates and risk of complications are taken into account when counseling women on the intended mode of birth, we analyzed the occurrence of adverse out- comes, showing no differences between the groups. Harper et al also found no differences in uterine rupture rates between prior cesarean before or after 34 weeks. ${ }^{11}$ Rochelson et al analyzed 25 cases of uterine rupture in a case-control design and found that a previous cesarean before or at 36 weeks is associated with a five times higher risk of uterine rupture as compared with previous term caesarean. ${ }^{12}$ However, the cases and controls differed on more characteristics than only the history of preterm cesarean that may explain these differences. In the PRN database, uterine rupture is not a compulsory item to score, so we are unable to draw any firm conclusion on the specific rate of uterine ruptures. However, rates of postpartum hemorrhage, low Apgar scores, and neonatal deaths, which can be direct outcomes of uterine rupture, did not differ.

\section{Strengths and Limitations}

A research question as ours can only be answered by large observational cohort studies. The strength of our study is that it includes the largest amount of pregnancies as compared with studies that have been conducted on this subject so far, enabling us to provide more detailed information in counseling the specific group of women who are pregnant after having had a preterm cesarean. A limitation of this study is that our data stem from a database with a confined set of items. The first disadvantage we experienced was not being able to include all possible confounders in the multivariate analysis, such as body mass index and smoking, and not being able to report on all possible outcomes reliably, such as uterine rupture. Second, as already mentioned, reasons for obstetrical interventions cannot be deduced from the database. It would be informative to learn more about the indications for caesareans as well as indications for the relatively high induction rate. A possible explanation is that care providers filling out the database entry form saw the use of uterotonics during labor, a means of labor induction, while in fact it was used for labor augmentation. Third, we were not able to rule out selection bias. The decision on how to deliver is made by the woman, her partner, and her obstetrician. Patients who attempted vaginal birth after cesarean in our cohort might be the ones encouraged by obstetricians who estimated these women to have fairly good success chances. However, the fact that approximately four in every five women in our cohort opted for trial of labor, means there will by definition be heterogeneity in this group, which pleads against a strong selection bias.

\section{Conclusion}

In current obstetric practice, individualized information on the chance of success of trial of labor after cesarean is desired by women and obstetricians. The effect of a preterm cesarean on subsequent trial of labor has been assessed by studies with relatively small sample sizes or no division in subgroups. This study included 4,342 women with a previous preterm cesarean who opted for a subsequent trial of labor, showing that success rates are high and rates of adverse outcomes are low. 
714 Effect of a Preterm Cesarean on Subsequent Term Trial of Labor Rietveld et al.

Funding

None.

\section{Conflict of Interest}

None.

\section{Acknowledgments}

The authors would like to thank all Dutch perinatal healthcare professionals for registration of perinatal information. The authors would like to thank the Foundation of the Netherlands Perinatal Registry (PRN) for permission to use the registry data (registration number 16.75).

\section{References}

1 Betrán AP, Ye J, Moller AB, Zhang J, Gülmezoglu AM, Torloni MR. The increasing trend in caesarean section rates: global, regional and national estimates: 1990-2014. PLoS One 2016;11(02): e0148343

2 Landon MB, Hauth JC, Leveno KJ, et al; National Institute of Child Health and Human Development Maternal-Fetal Medicine Units Network. Maternal and perinatal outcomes associated with a trial of labor after prior cesarean delivery. N Engl J Med 2004;351(25): 2581-2589

3 Declercq E, Barger M, Cabral HJ, et al. Maternal outcomes associated with planned primary cesarean births compared with planned vaginal births. Obstet Gynecol 2007;109(03): 669-677

4 Liu S, Liston RM, Joseph KS, Heaman M, Sauve R, Kramer MS; Maternal Health Study Group of the Canadian Perinatal Surveillance System. Maternal mortality and severe morbidity associated with low-risk planned cesarean delivery versus planned vaginal delivery at term. CMAJ 2007;176(04):455-460

5 Hook B, Kiwi R, Amini SB, Fanaroff A, Hack M. Neonatal morbidity after elective repeat cesarean section and trial of labor. Pediatrics 1997;100(3 Pt 1):348-353

6 American College of Obstetricians and Gynecologists. ACOG Practice bulletin no. 115: vaginal birth after previous cesarean delivery. Obstet Gynecol 2010;116(2 Pt 1):450-463

7 NVOG. Zwangerschap en bevalling na een voorgaande sectio caesarea. [Guideline Pregnancy and delivery after a previous cesarean section of the Dutch Society of Obstetrics and Gynaecology]; 2010. Available at: www.nvog.nl. Accessed July 29, 2017
8 Metz T. Use of calculators and models for predicting vaginal birth after a previous cesarean delivery. In: Barns VA (Ed.), UpToDate. Available at: www.uptodate.com/contents/choosing-the-routeof-delivery-after-cesarean-birth. Accessed October 6, 2018

9 Binder T, Hájek Z, Zoban P, Plavka R. Conducting labor in women with previous caesarean section in a low gestational week. A prospective case-controlled study. Gynecol Obstet Invest 2008;66 (03):197-202

10 Kwee A, Smink M, Van Der Laar R, Bruinse HW. Outcome of subsequent delivery after a previous early preterm cesarean section. J Matern Fetal Neonatal Med 2007;20(01):33-37

11 Harper LM, Cahill AG, Stamilio DM, Odibo AO, Peipert JF, Macones GA. Effect of gestational age at the prior cesarean delivery on maternal morbidity in subsequent VBAC attempt. Am J Obstet Gynecol 2009;200(03):276.e1-276.e6

12 Rochelson B, Pagano M, Conetta L, et al. Previous preterm cesarean delivery: identification of a new risk factor for uterine rupture in VBAC candidates. J Matern Fetal Neonatal Med 2005;18(05): 339-342

13 Stichting PRN. Perinatale Zorg in Nederland 2007. [Perinatal Care in the Netherlands]. Utrecht: Stichting Perinatale Registratie Nederland; 2009

14 Méray N, Reitsma JB, Ravelli AC, Bonsel GJ. Probabilistic record linkage is a valid and transparent tool to combine databases without a patient identification number. J Clin Epidemiol 2007; 60(09):883-891

15 Tromp M, Ravelli AC, Méray N, Reitsma JB, Bonsel GJ. An efficient validation method of probabilistic record linkage including readmissions and twins. Methods Inf Med 2008;47(04):356-363

16 Schaaf JM, Hof MH, Mol BW, Abu-Hanna A, Ravelli AC. Recurrence risk of preterm birth in subsequent singleton pregnancy after preterm twin delivery. Am J Obstet Gynecol 2012;207(04):279. e1-279.e7

17 Peeters LLH, Scherjon SA. De normale zwangerschap: de zwangere vrouw. [The normal pregnancy: the pregnant women.] In Heineman MJ, ed. Obstetrie en gynaecologie pp. 254-255. Maarssen, Elsevier gezondheidszorg; 2007

18 Lappen JR, Hackney DN, Bailit JL. Outcomes of term induction in trial of labor after cesarean delivery: analysis of a modern obstetric cohort. Obstet Gynecol 2015;126(01):115-123

19 Grobman WA, Lai Y, Landon MB, et al; National Institute of Child Health and Human Development (NICHD) Maternal-Fetal Medicine Units Network (MFMU). Development of a nomogram for prediction of vaginal birth after cesarean delivery. Obstet Gynecol 2007;109(04):806-812 